\title{
Trends in endovascular aneurysm repair research: bibliometric analysis from 1994 to 2017
}

\author{
Ji Woong Hwang', Heungman Jun² \\ ${ }^{1}$ Department of Surgery, Kangnam Sacred Heart Hospital, Hallym University College of Medicine, Seoul, Korea \\ ${ }^{2}$ Department of Surgery, Inje University I/san Paik Hospital, Inje University College of Medicine, Goyang, Korea
}

\begin{abstract}
Purpose: Since endovascular aneurysm repair (EVAR) was first introduced in 1991, it has undergone rapid technical and quantitative developments. We analyzed the characteristics and trends of EVAR research through bibliometric analysis. Methods: Comprehensive online searches focused on EVAR were performed from January 1994 to August 2017. The following information was collected: title, year of publication, countries' contribution, authorship, subspecialty, institution, subject category, and top 10 cited articles.

Results: A significant increase was demonstrated globally in the number of annual publications on EVAR. The highest number of publications was from the United States ( $n=849,35.08 \%$ ), followed by England ( $n=343,14.17 \%$ ), and the institutions with highest number of publications were Stanford University ( $n=61,2.52 \%$ ) and Skane University Hospital Malmo ( $n=45,1.86 \%$ ). The Journal of Vascular Surgery published approximately one quarter of the total publications. Vascular surgeons produced the most publications ( $n=1871,78.14 \%$ ), followed by radiologists $(n=377,15.58 \%$ ) and cardiologists ( $n=73,3.02 \%$ ). The most studied topics on EVAR were complications and procedures. The number of publications on complex EVAR and EVAR in juxtarenal aneurysm has increased more from 2013 to 2017 (5.1\%, $9.5 \%$ ) compared with from 1998 to $2002(2.1 \%, 1.8 \%)$.

Conclusion: Our bibliometric analysis showed the characteristics and trends of publications on EVAR over a period of 25 years. The results of the bibliometric analysis revealed the quantitative improvements of publications and the qualitative improvements in challenging EVAR.
\end{abstract}

[Ann Surg Treat Res 2019;96(2):47-52]

Key Words: Aortic aneurysm abdominal, Endovascular procedure, Bibliometrics

\section{INTRODUCTION}

Due to developments such as extended life expectancy and increase in screening, annual incidences of abdominal aortic aneurysm (AAA) have been on the rise [1], and an annual mortality of over 10,000 deaths due to AAA has been reported from 2010 in the United States [2]. For these reasons, screening and early intervention are crucial to tackling AAA. After the first open surgical repair for AAA by Freeman and Leeds was successfully done in 1951, surgery has become a popular treatment for AAA [3]. In 1991, Parodi et al. [4] first introduced the endovascular aneurysm repair (EVAR) method. Since then, EVAR has undergone rapid technical, as well as quantitative, developments. Despite the extensive use of the AAA repair method, patients prefer EVAR, which is less invasive, and as a result, most cases of elective repairs now involve using EVAR [5].

Recently, numerous bibliometric analyses on various topics have been announced. Bibliometric analysis involves analyzing the research performance of authors, countries, journals, institutions, and trends of publications with similar topics
Received August 9, 2018, Revised October 4, 2018,

Accepted October 12, 2018

\section{Corresponding Author: Heungman Jun}

Department of Surgery, Inje University Ilsan Paik Hospital, Inje University College of Medicine, 170 Juhwa-ro, Ilsanseo-gu, Goyang 10380, Korea

Tel: +82-31-910-7947, Fax: +82-31-910-7784

E-mail: midasia@hanmail.net

ORCID code: https://orcid.org/0000-0003-2530-4388
Copyright (C) 2019, the Korean Surgical Society

(c) Annals of Surgical Treatment and Research is an Open Access Journal. All articles are distributed under the terms of the Creative Commons Attribution NonCommercial License (http://creativecommons.org/licenses/by-nc/4.0/) which permits unrestricted non-commercial use, distribution, and reproduction in any medium, provided the original work is properly cited. 
[6]. It facilitates understanding of characteristics and trends of a specific focus area. In the United Kingdom, after the first multicenter randomized controlled trial comparing EVAR and open repair began in 1999, a lot of research on EVAR has been conducted [7]. The current study research aims to analyze the characteristics and trends of EVAR research, which has made many technical advancements over the last 20 years, through bibliometric analysis.

\section{METHODS}

The Institutional Review Board approved the review of medical research using publicly available databases (approval number: 2018-07-021). To identify articles on EVAR, a comprehensive online search was performed using the database of the Web of Science Core Collection of Thomson Reuters on September 1, 2017. The following terms were used to retrieve related publications from January 1994 to August 2017: ("EVAR") OR ("endovascular aneurysm repair") OR ("endovascular aortic aneurysm repair"). Only EVAR for AAA was included, regardless of iliac artery aneurysm involvement. Aortic aneurysm involving thoracic aortic aneurysm and aortic pathologies including periaortic inflammation, traumatic aortic injury, and aortic dissection were excluded. EVAR in isolated iliac artery aneurysm was excluded. With regard to publication type, only articles and reviews were included, while letters, notes, and editorials were excluded.

All data were independently collected by two reviewers (JWH and HJ) and journal selection, article identification, and analyses were performed, with disagreements resolved by consensus. The data were imported to Microsoft Excel 2016 for analysis.

The following information was collected and analyzed: total number of publications and trends of global contributions to EVAR, title, year of publication, countries' contribution, authorship, subspecialty, institution, subject category, impact factor, and the 10 most-cited articles. In the case of more than one category in an institution, country, and subspecialty, the category of the corresponding author was adopted. Among these factors, subspecialties were classified as vascular surgery, radiology, cardiology, basic research, etc. Only the top 10 ranked publications were considered. If 2 or more measurements had the same ranking, those with more citations were given priority. The articles were ultimately divided into 8 topic-based groups after the 2 reviewers classified 2,420 articles by manually reviewing the abstracts. The topics were classified as follows: (1) comparisons between EVAR and open repair, (2) EVAR in ruptured aneurysm, (3) complex EVAR including hostile neck, (4) surveillance after EVAR, (5) EVAR in juxtarenal aneurysm, (6) outcomes of EVAR, (7) procedures of EVAR including stent graft products and technique, and (8) complications of EVAR including endoleak. In case of overlapping topics, the reviewers selected the proper topic after discussion.

\section{RESULTS}

A total number of 4,710 publications on EVAR from January 1994 to August 2017 were indexed in the Web of Science Core Collection of Thomson. Among these, articles that were not written in English $(n=49)$ were excluded. Publications other than original articles and reviews $(\mathrm{n}=1,676)$ were excluded. The articles that not on the subject of this study $(n=565)$ were also excluded. In the end, a total of 2,420 articles were included in the current study.

Since the first publication was introduced in 1994 under the name of EVAR, a significant increase in the number of annual publications was observed globally (Fig. 1). A total of 39 countries contributed to the 2,420 publications included in this study. The largest number of publications in the field of EVAR was from the United States ( $\mathrm{n}=849,35.08 \%)$, followed by England $(n=343,14.17 \%)$, and the Netherlands $(n=197,8.14 \%$ ) (Fig. 2). Among them, 49 institutions produced more than 10 publications of EVAR, led by Stanford University $(n=61$, $2.52 \%$ ), followed by Skane University Hospital Malmo ( $\mathrm{n}=$ 45, 1.86\%), and Catharina Hospital $(n=42,1.74 \%)$ (Table 1). Approximately 1,300 authors contributed to the total number of publications. Analysis of the 10 most productive corresponding authors revealed that 4 authors were from the United States, 3 from the Netherlands, 2 from England, and 1 from France, and all of them were vascular surgeons. Among them, 20 authors published 10 or more articles, led by Zarins CK $(n=24)$, followed by Schermerhorn ML $(n=18)$, and Mehta M $(n=17)$ (Table 2).

The studies on EVAR for AAA were published in 232 different journals. The Journal of Vascular Surgery published

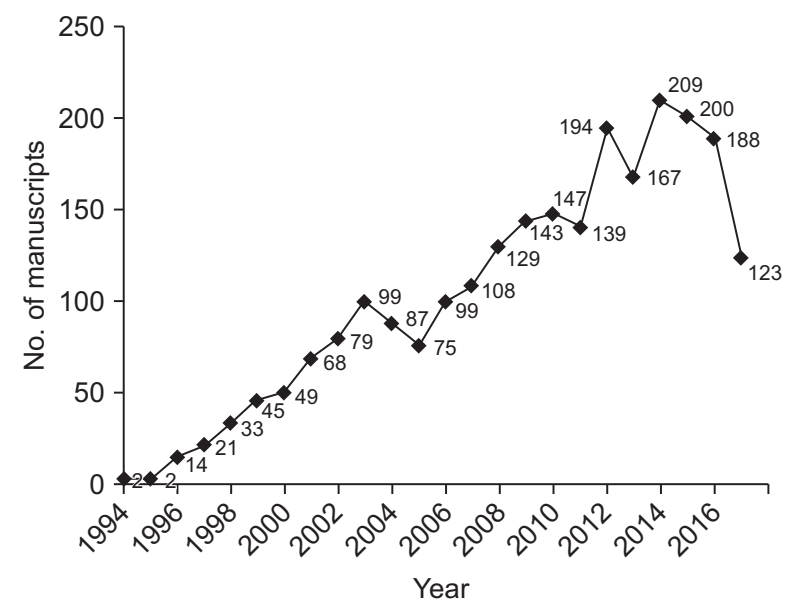

Fig. 1. The number of annual publications on endovascular aneurysm repair from 1994 to 2017. 
approximately one quarter of the total papers and generated the largest number of citations, with 608 papers and a total of 22,464 citations, whereas, the British Journal of Surgery had the highest average number of citations per article (Table 3). With regard to specialty contribution, vascular surgeons produced the highest number of publications ( $\mathrm{n}=1,871,78.14 \%$ ), followed by radiologists $(n=377,15.58 \%)$, and cardiologists $(n=73$, 3.02\%) (Fig. 3). Of note, the authors of the basic research field also produced 30 publications focusing on new techniques and materials for stent graft. The remaining authors of other clinical fields including anesthesiology, nephrology, neurology, and neurosurgery published 50 articles. Of the top 10 most cited publications, seven featured the comparison of open and endovascular repair of AAA s. Two publications focused on the procedure for EVAR, and 1 publication focused on the complications of EVAR (Table 4).

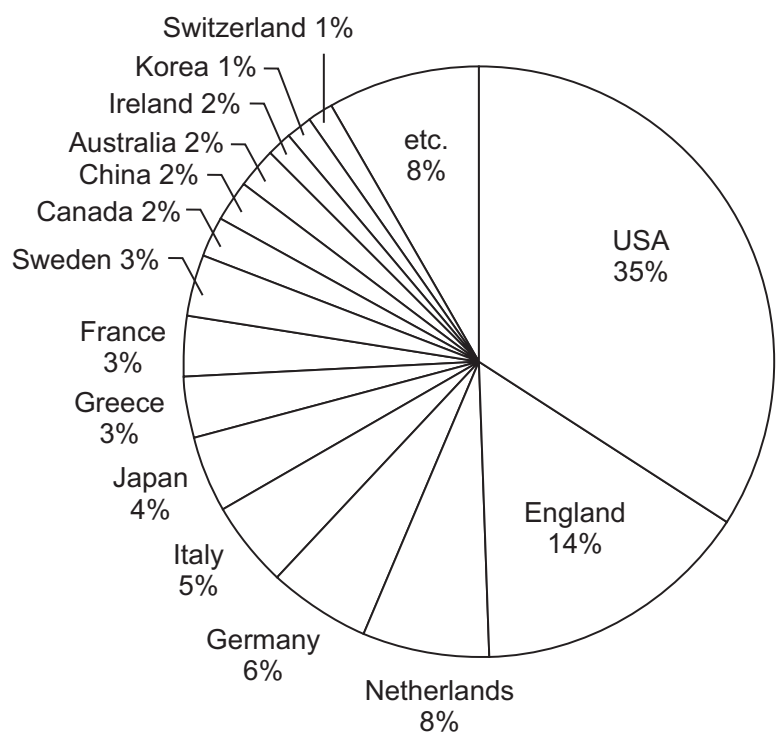

Fig. 2. Country contribution of publications on endovascular aneurysm repair from 1994 to 2017.
The most studied trends in publications for EVAR from 1994 to 2017 were complications and procedures. The topics on complex EVAR and EVAR in juxtarenal aneurysm have increased further from 2013 (5.1\%) to 2017 (9.5\%) compared to the increase from 1998 (2.1\%) to 2002 (1.8\%). On the other hand, the topic of outcomes of EVAR from 2013 to 2017 (13.4\%) has decreased, compared to 15 years ago (20.8\%) (Fig. 4).

\section{DISCUSSION}

After Parodi first introduced EVAR in 1991 [4], this method has continued its rapid development. In the beginning, aortouniiliac tube stent grafts with femorofemoral bypass were used. Later, bifurcated grafts were introduced, which continue to be widely used today [8]. Recent EVAR shows characteristics such as flexibility of the stent grafts, advanced fixation system, low-profile delivery, and new technologies, including fenestrated and branched grafts, and has expanded indications of EVAR and made great advancements [9]. The purpose of

Table 2. Top 10 corresponding authors with the highest number of publications on endovascular aneurysm repair from 1994 to 2017

\begin{tabular}{rlrrl}
\hline Rank & \multicolumn{1}{c}{ Author } & Number & TC & \multicolumn{1}{c}{ Country } \\
\hline 1 & Zarins, CK & 24 & 1,382 & USA \\
2 & Schermerhorn, ML & 18 & 887 & USA \\
3 & Mehta, M & 17 & 570 & USA \\
4 & Greenhalgh, RM & 16 & 3,292 & England \\
5 & Blankensteijn, JD & 15 & 2,457 & Netherlands \\
6 & Verhoeven, ELG & 15 & 424 & Netherlands \\
7 & Haulon, S & 15 & 184 & France \\
8 & Saratzis, A & 15 & 167 & England \\
9 & Buth, J & 14 & 1,457 & Netherlands \\
10 & Chuter, TAM & 14 & 643 & USA \\
\hline \hline
\end{tabular}

TC, total citation.

Table 1. Top 10 productive institutions with the highest number of publications on endovascular aneurysm repair from 1994 to 2017

\begin{tabular}{rlrrr}
\hline Rank & & No. (\%) & Country & TC \\
\hline 1 & Stanford University & $61(2.52)$ & USA & 1,940 \\
2 & Skane University Hospital Malmo & $45(1.86)$ & Sweden & 1,290 \\
3 & Catharina Hospital & $42(1.74)$ & Netherlands & 2,424 \\
4 & St George's University Hospital & $41(1.69)$ & England & 1,007 \\
5 & Royal Liverpool University Hospital & $40(1.65)$ & England & 1,692 \\
6 & University Medical Center Utrecht & $39(1.61)$ & Netherlands & 1,870 \\
7 & Mayo Clinic & $35(1.45)$ & USA & 584 \\
7 & Imperial College of Science, Technology and Medicine, University of London & $35(1.45)$ & England & 3,755 \\
7 & Icahn School of Medicine at Mount Sinai & $35(1.45)$ & USA & 943 \\
10 & University of Pennsylvania & $34(1.40)$ & USA & 1,576 \\
\hline
\end{tabular}

TC, total citations. 
Table 3. Top 10 journals with the highest number of publications on endovascular aneurysm repair from 1994 to 2017

\begin{tabular}{|c|c|c|c|c|c|}
\hline Rank & Journal & No. $(\%)$ & $\mathrm{TC}$ & $C / A^{a)}$ & $I^{b)}$ \\
\hline 1 & Journal of Vascular Surgery & $608(25.12)$ & 22,464 & 36.95 & 3.536 \\
\hline 2 & European Journal of Vascular and Endovascular Surgery & $234(9.67)$ & 6,034 & 25.79 & 4.061 \\
\hline 3 & Journal of Endovascular Therapy & $219(9.05)$ & 3,940 & 17.99 & 2.838 \\
\hline 4 & Annals of Vascular Surgery & $212(8.76)$ & 1,987 & 9.37 & 1.145 \\
\hline 5 & Journal of Cardiovascular Surgery & $86(3.55)$ & 755 & 8.78 & 2.179 \\
\hline 6 & Journal of Vascular and Interventional Radiology & $72(2.98)$ & 1,674 & 23.25 & 2.780 \\
\hline 7 & Cardiovascular and Interventional Radiology & $67(2.77)$ & 816 & 12.18 & 2.191 \\
\hline 8 & Vascular and Endovascular Surgery & $66(2.73)$ & 235 & 3.56 & 1.094 \\
\hline 9 & Vascular & $65(2.69)$ & 295 & 4.45 & 0.733 \\
\hline 10 & British Journal of Surgery & $43(1.78)$ & 1,712 & 39.81 & 5.899 \\
\hline
\end{tabular}

TC, total citation; C/A, average numbers of citations; IF, impact factor.

${ }^{\text {a) }}$ Average number of citations per article calculated by dividing the total citation by number of articles for each journal. ${ }^{\text {b) }} \mathrm{Calculated}$ using Journal Citation Reports for the year 2016.

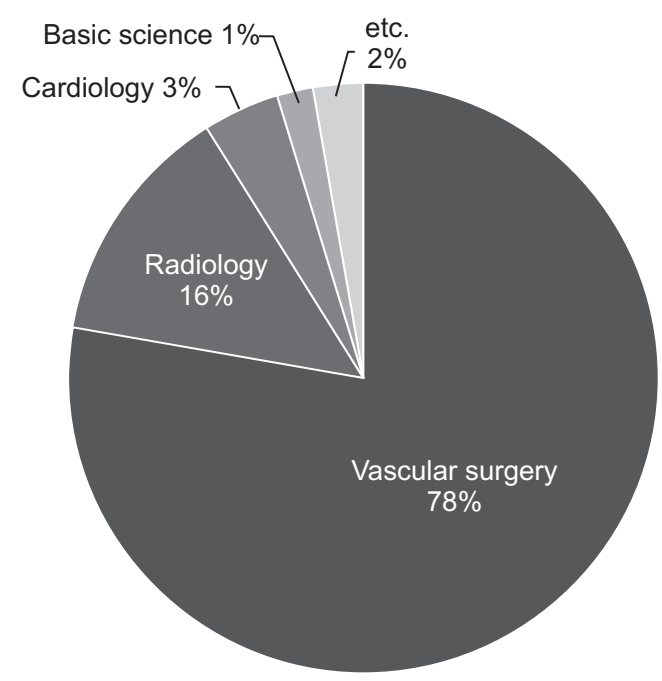

Fig. 3. Specialty contribution of publications on endovascular aneurysm repair from 1994 to 2017.

EVAR is the exclusion of the aneurysmal sac from the aortic circulation. When perigraft flow is present, it is called an endoleak. In this circumstance, it may result in sac expansion and delayed rupture [10]. With the recent increase in difficult EVARs, including juxtarenal aneurysm and hostile neck, interest in complications, including endoleak, has increased as well. Similarly, in this study, research on the outcomes of EVAR has decreased over time, but study of complex EVAR and EVAR in juxtarenal aneurysm has increased.

Bibliometric analysis has been used to assess the scientific productivity in medical fields and the quality of academic publications [11]. The citation of articles is an effective method of advancing and sharing scientific knowledge, and the number of citations is a reliable indicator of the quality and impact of articles [12].

Like EVAR use in the treatment of AAA, the number of annual publications on EVAR has rapidly increased over the past 20 years. The United States produced 35\% of the publications on EVAR and 25\% of them have been published in the Journal of Vascular Surgery. Various departments, including vascular surgery, cardiology, and radiology $(78 \%, 15 \%, 3 \%)$ published articles on EVAR. Recently, EVAR has become the standard treatment for AAA with collaborations and competitions of various departments. The USA and Europe have produced $80 \%$ of the world's publications on EVAR, which shows a lack of regional and institutional balance. The most cited study on EVAR is a randomized trial conducted by Prinssen et al. [13] comparing conventional and endovascular repair of AAA, published in the New England Journal of Medicine in 2004. In the analyses according to institutions, Stanford University had the most publications on EVAR; however, the Imperial College of Medicine had the highest total number of citations. The common topics of publications on EVAR are complications, procedures, and outcomes.

Our research had several limitations. First, as all the publications on EVAR from 1994 to 2017 were collected and analyzed, we were unable to categorize the citations. Thus, numeric analysis on each parameter was possible, but it was difficult to reflect the quality and impact of publications according to the citations. Second, as the title of the first publication about EVAR is "Intraluminal graft implantation for abdominal aortic aneurysm" [4], this article was not identified or selected as about EVAR. Additionally, stent grafts that were not marked as for EVAR were not selected. Third, affiliations or topics were sometimes unclear, and in such cases, two reviewers discussed the issue to arrive a decision. Another limitation was that only corresponding authors were considered in the analysis; thus the roles of all other authors were not fully reflected.

In conclusion, our bibliometric analysis showed the characteristics and trends of publications on EVAR over a period 
Table 4. Top 10 cited articles on endovascular aneurysm repair (EVAR) from 1994 to 2017 [7,13-21]

\begin{tabular}{|c|c|c|c|}
\hline Author & Country & Title & TC \\
\hline Prinssen et al. [13] & The Net & $\begin{array}{l}\text { A randomized trial comparing conventional and endovascular repair of abdominal } \\
\text { aortic aneurysms }\end{array}$ & 1,072 \\
\hline Greenhalgh et al. [7] & England & $\begin{array}{l}\text { Comparison of endovascular aneurysm repair with open repair in patients } \\
\text { with abdominal aortic aneurysm (EVAR trial 1), 30-day operative mortality results: } \\
\text { randomized controlled trial }\end{array}$ & 1,032 \\
\hline Chaikof et & U & Reporting standards for endovascular aortic aneurysm repair & 789 \\
\hline Greenhalgh et al. [15] & England & $\begin{array}{r}\text { Endov } \\
\text { aortic }\end{array}$ & 719 \\
\hline 6] & $\mathrm{Er}$ & Endovascular versus open repair of abdominal aortic aneurysm & 631 \\
\hline Blanke & The Netherlands & $\begin{array}{l}\text { ar outcomes after conventional or endovascular repair of abdominal aortic } \\
\text { sms }\end{array}$ & 549 \\
\hline Lederle et al. [18] & USA & $\begin{array}{l}\text { following endovascular vs open repair of abdominal aortic } \\
\text { a randomized trial }\end{array}$ & 450 \\
\hline Harris et al. [19] & England & $\begin{array}{l}\text { Incidence and risk factors of late rupture, conversion, and death after } \\
\text { endovascular repair of infrarenal aortic aneurysms: The EUROSTAR experience }\end{array}$ & 446 \\
\hline De Bruin & & outcome of open or endovascular repair of abdominal aortic aneurysm & 420 \\
\hline Parodi [21] & Argentina & Endovascular repair of abdominal aortic-aneurysms and other arterial lesions & 404 \\
\hline
\end{tabular}

$\mathrm{TC}$, total citation.

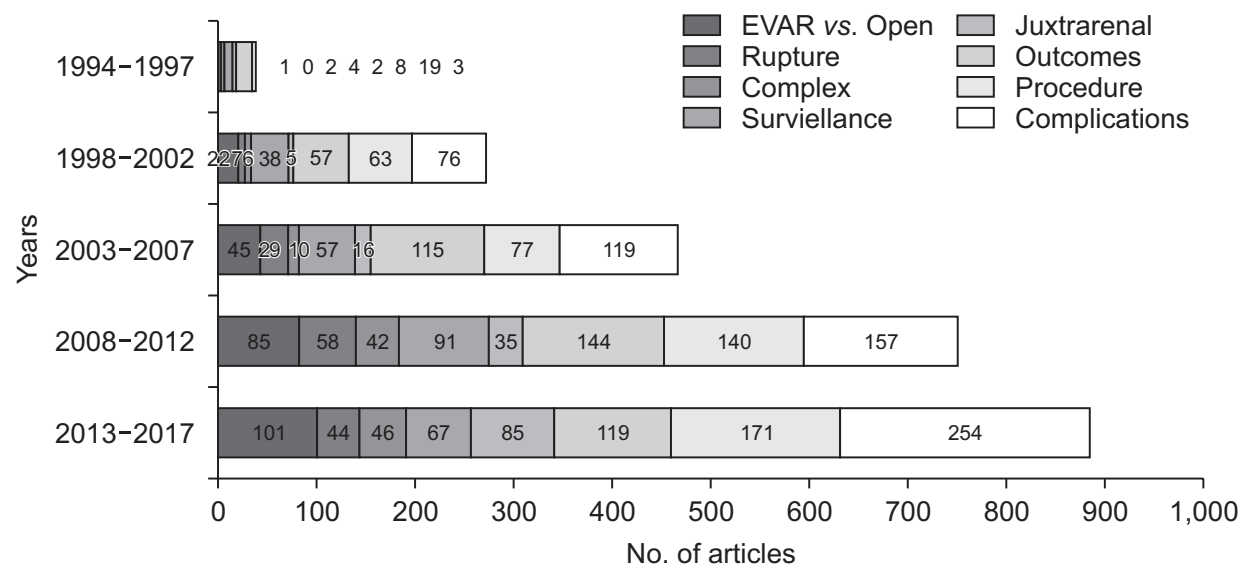

Fig. 4. Changes in trends of publications on endovascular aneurysm repair (EVAR) from 1994 to 2017. of 25 years. The results of the bibliometric analysis revealed the quantitative improvements of publications and the qualitative improvements in technically advanced EVARs.

\section{CONFLICTS OF INTEREST}

No potential conflict of interest relevant to this article was reported.

\section{ACKNOWLEDGEMENTS}

This research was supported by Hallym University Research Fund 2018 (HURF-2018-17).

\section{REFERENCES}

1. Kent KC, Zwolak RM, Jaff MR, Hollenbeck ST, Thompson RW, Schermerhorn ML, et al. Screening for abdominal aortic aneurysm: a consensus statement. J Vasc
Surg 2004:39:267-9.

2. Murphy SL, Xu J, Kochanek KD. Deaths: final data for 2010. Natl Vital Stat Rep 2013;61:1-117.
3. Freeman ME, Leeds FH. Vein inlay graft in the treatment of aneurysms and thrombosis of the abdominal aorta; a preliminary communication with report of 3 
cases. Angiology 1951:2:579-87.

4. Parodi JC, Palmaz JC, Barone HD. Transfemoral intraluminal graft implantation for abdominal aortic aneurysms. Ann Vasc Surg 1991;5:491-9.

5. Schermerhorn ML, Buck DB, O'Malley AJ, Curran T, McCallum JC, Darling J, et al. Long-term outcomes of abdominal aortic aneurysm in the medicare population. $\mathrm{N}$ Engl J Med 2015:373:328-38.

6. Terttu Luukkonen. Bibliometrics and evaluation of research performance. Annals of Medicine 1990;22:143-50.

7. Greenhalgh RM, Brown LC, Kwong GP, Powell JT, Thompson SG; EVAR trial participants. Comparison of endovascular aneurysm repair with open repair in patients with abdominal aortic aneurysm (EVAR trial 1), 30-day operative mortality results: randomised controlled trial. Lancet 2004;364:843-8.

8. Chuter TA, Risberg B, Hopkinson BR, Wendt G, Scott RA, Walker PJ, et al. Clinical experience with a bifurcated endovascular graft for abdominal aortic aneurysm repair. J Vasc Surg 1996:24:65566.

9. Steuer J, Lachat M, Veith FJ, Wanhainen A. Endovascular grafts for abdominal aortic aneurysm. Eur Heart J 2016;37:145-51.

10. White GH, Yu W, May J, Chaufour X, Stephen MS. Endoleak as a complication of endoluminal grafting of abdominal aortic aneurysms: classification, incidence, diagnosis, and management. J Endovasc Surg 1997;4:152-68.

11. Asghar I, Cang S, Yu H. Assistive technology for people with dementia: an overview and bibliometric study. Health Info Libr J 2017;34:5-19.

12. Moed HF. New developments in the use of citation analysis in research evaluation. Arch Immunol Ther Exp (Warsz) 2009:57: 13-8.

13. Prinssen M, Verhoeven EL, Buth J, Cuypers PW, van Sambeek MR, Balm $\mathrm{R}$, et al. A randomized trial comparing conventional and endovascular repair of abdominal aortic aneurysms. N Engl J Med 2004:351:1607-18.

14. Chaikof EL, Blankensteijn JD, Harris PL, White GH, Zarins CK, Bernhard VM, et al. Reporting standards for endovascular aortic aneurysm repair. J Vasc Surg 2002;35:1048-60.

15. EVAR trial participants. Endovascular aneurysm repair versus open repair in patients with abdominal aortic aneurysm (EVAR trial 1): randomised controlled trial. Lancet 2005:365:2179-86.

16. United Kingdom EVAR Trial Investigators, Greenhalgh RM, Brown LC, Powell JT, Thompson SG, Epstein D, et al. Endovascular versus open repair of abdo- minal aortic aneurysm. N Engl J Med 2010;362:1863-71.

17. Blankensteijn JD, de Jong SE, Prinssen M, van der Ham AC, Buth J, van Sterkenburg $\mathrm{SM}$, et al. Two-year outcomes after conventional or endovascular repair of abdominal aortic aneurysms. N Engl J Med 2005;352:2398-405.

18. Lederle FA, Freischlag JA, Kyriakides TC, Padberg FT Jr, Matsumura JS, Kohler TR, et al. Outcomes following endovascular vs open repair of abdominal aortic aneurysm: a randomized trial. JAMA 2009;302:1535-42.

19. Harris PL, Vallabhaneni SR, Desgranges P, Becquemin JP, van Marrewijk C, Laheij RJ. Incidence and risk factors of late rupture, conversion, and death after endovascular repair of infrarenal aortic aneurysms: the EUROSTAR experience. European Collaborators on Stent/graft techniques for aortic aneurysm repair. J Vasc Surg 2000;32:739-49.

20. De Bruin JL, Baas AF, Buth J, Prinssen M, Verhoeven EL, Cuypers PW, et al. Longterm outcome of open or endovascular repair of abdominal aortic aneurysm. N Engl J Med 2010;362:1881-9.

21. Parodi JC. Endovascular repair of abdominal aortic aneurysms and other arterial lesions. J Vasc Surg 1995:21:54955. 